\title{
Fabrication of Porous and Nanoporous Aluminum via Selective Dissolution of Al-Zn Alloys
}

\author{
Oscar Marcelo Suárez, ${ }^{1}$ Elvin G. Estremera, ${ }^{2}$ Rafael Soler, ${ }^{3}$ \\ Amarilis Declet, ${ }^{2}$ and Arturo J. Hernández-Maldonado ${ }^{4}$ \\ ${ }^{1}$ General Engineering Department, University of Puerto Rico, P.O. Box 9000, Mayagüez, PR 00681, USA \\ ${ }^{2}$ Mechanical Engineering Department, University of Puerto Rico, P.O. Box 9000, Mayagüez, PR 00681, USA \\ ${ }^{3}$ Theoretical and Applied Mechanics Program, Northwestern University, 633 Clark Street, Evanston, IL, USA \\ ${ }^{4}$ Chemical Engineering Department, University of Puerto Rico, P.O. Box 9000, Mayagüez, PR 00681, USA
}

Correspondence should be addressed to Oscar Marcelo Suárez; oscarmarcelo.suarez@upr.edu

Received 8 March 2014; Revised 12 July 2014; Accepted 12 July 2014; Published 24 August 2014

Academic Editor: Yucel Birol

\begin{abstract}
Copyright (C) 2014 Oscar Marcelo Suárez et al. This is an open access article distributed under the Creative Commons Attribution License, which permits unrestricted use, distribution, and reproduction in any medium, provided the original work is properly cited.

Porous and nanoporous aluminum have been fabricated via selective dissolution. Al-Zn alloys were dealloyed in an aqueous solution of nitric acid to selectively dissolve zinc. Fast solidification methods permitted to adjust the precursor microstructure of the parent alloy in order to induce supersaturation of zinc in aluminum. An electric potential applied during corrosion affected the final morphology of porosity. Electronic imaging evinced the presence of regions with less than $100 \mathrm{~nm}$ diameter pores. This nanoporosity was only present in electrochemically dealloyed samples. We observed two types of porosity in dealloyed samples: a primary porosity resulting from the selective removal of zinc-rich interdendritic phases and a secondary porosity resulting from nanoporosity evolution inside zinc-supersaturated dendrites.
\end{abstract}

\section{Introduction}

Nanoporous metals are composed of a metallic ligament network and an open cell interconnected structure (pores). Their most significant feature is their high surface area, which generates a potential for many applications [1-4]. While there are various ways of manufacturing nanoporous metals, the easiest and least expensive method is selective dissolution or dealloying. In this method a less noble species or phase can be selectively removed from a metallic solid solution or alloy [5]. As it is well known, the most noble metals in a galvanic table are usually precious metals. Hence, nanoporous metals can be expensive to produce. This is why new studies focus on the fabrication of nanoporous metals with low or null precious metal loading [6-8].

In many applications, aluminum is selected as the material to be removed (less noble) and remains one of the most popular choices [3]. The main reason for its selection is its high activity, ease to be alloyed with many desired metals, abundance, and low cost. However, such high activity does not necessarily close the possibility for aluminum to become the more noble metal. If there exists a binary system where aluminum is nobler, it might be possible to create nanoporous aluminum via dealloying. At the moment of writing this paper, to our knowledge there were scarce accounts available in the literature about the use of aluminum as the noble specie for a dealloying process and no published reports about nanoporous aluminum (NPAl). As a consequence, the challenge of the present research was to fabricate relatively inexpensive nanoporous aluminum via chemical dealloying.

\section{Experimental Procedure}

2.1. Materials Selection. Traditional fabrication techniques use as parent alloys binary isomorphous systems, that is, systems with single-phase solid solubility across all compositions. This homogeneity is the preferred scenario for nanoporosity evolution [9]. The Al-Zn binary system does not have this type of solubility although zinc has a large 
solubility in aluminum. In a typical Al-Zn binary alloy microstructure aluminum-rich dendrites contain dissolved zinc, while zinc solid solution is present around the dendrite arms. If such $\mathrm{Al}-\mathrm{Zn}$ alloy is to be selectively leached to remove $\mathrm{Zn}$, nanoporosity formation would only take place inside the aluminum-rich areas while the rest of the porosity would result from pure $\mathrm{Zn}$ removal. To successfully create nanoporosity inside the aluminum-rich dendrite, we proposed that zinc atoms be forced inside the solid solution dendrite. In our work, the use of large solidification rates helps increase the metastable retention of $\mathrm{Zn}$ atoms in the $\mathrm{Al}$ solid solution, which becomes supersaturated. This reduces the amount of zinc around the dendrites and ultimately promotes the formation of a better precursor microstructure with the potential to create nanoporosity in ample regions of the alloy sample.

In order to observe the effects of concentration on final porosity, for the precursor alloys, we selected chemical compositions ranging from 15 at.\% to 70 at. $\% \mathrm{Zn}$ balanced with aluminum. To produce them we used $99.5 \%$ pure aluminum metal shots from Fisher Scientific and 99.9\% pure zinc pieces (1.5-7 $\mathrm{mm}$ in diameter) from Sigma Aldrich.

2.2. Alloy Fabrication. Both zinc and aluminum pieces were mixed and melted in a graphite crucible at $750^{\circ} \mathrm{C}$. A cover with carbon dioxide prevented further oxidation of the melts. After homogenization via mechanical stirring, the molten material was directly transferred from the crucible into a quenching media, that is, liquid nitrogen, to facilitate the formation of a finer microstructure via fast solidification. The actual solidification rate was estimated at $350^{\circ} \mathrm{C} / \mathrm{s}$. After quenching, $0.5 \mathrm{~mm}$ thick slices of the solidified sample were cut and polished to serve as test specimens.

2.3. Selective Dissolution. A $1 \mathrm{wt} \%$ water solution of nitric acid $\left(\mathrm{HNO}_{3}\right)$ allowed dissolving zinc selectively. Aluminum and zinc react different in nitric acid: aluminum is passivated while zinc dissolves. The chemical reaction involving the dissolution of zinc in $\mathrm{HNO}_{3}$ is $\mathrm{Zn}(\mathrm{s})+2 \mathrm{HNO}_{3}$ (aq) $\rightarrow$ $\mathrm{Zn}\left(\mathrm{NO}_{3}\right)_{2}(\mathrm{aq})+\mathrm{H}_{2}(\mathrm{~g})$.

The products of this reaction are zinc nitrate $\mathrm{Zn}\left(\mathrm{NO}_{3}\right)_{2}$ and hydrogen $\mathrm{H}_{2}$, which forms bubbles that became the visual indicator of the reaction. Zinc nitrate is in aqueous form and is not perceivable by the naked eye. The dissolution process was held for 24 hours and recurred to two methods. The first one, hereon called free corrosion, involved only the immersion of the sample into $50 \mathrm{~mL}$ of electrolyte solution at room temperature and using a magnetic stirrer. The second one, hereupon noted as electrochemical corrosion, involved the application of an electrical potential to the system. The purpose of using two dissolution methods (free and electrochemical) was to observe their effect on porosity morphology. No current density was measured or additional electrical/chemical analysis was performed for the intent of the present work was to become a proof of concept and to lay the ground for further ongoing research.

The electrochemical cell consisted of $50 \mathrm{~mL}$ of $\mathrm{HNO}_{3}$ solution contained in a $500 \mathrm{~mL}$ beaker. A $0.5 \mathrm{~cm}$ thick, $0.5 \mathrm{~cm}$

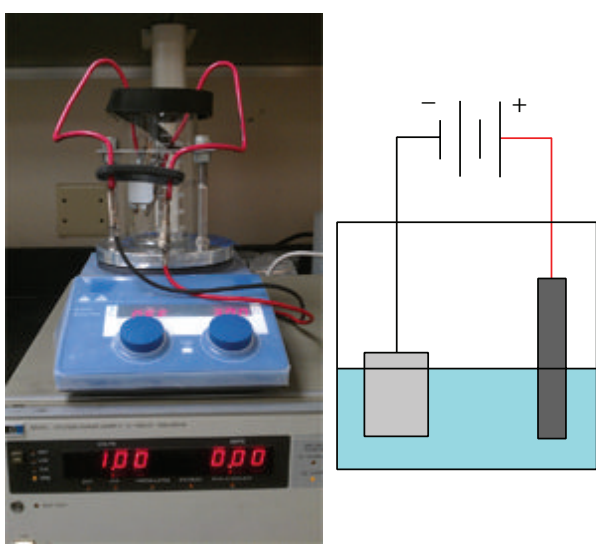

FIGURE 1: Electrochemical corrosion setup.

wide, and $5 \mathrm{~cm}$ long graphite rod was used as the positive electrode while the sample was the negative one (Figure 1). We submerged the electrodes approximately $1 \mathrm{~cm}$ into the corrosive solution and kept the distance between electrodes at $50 \mathrm{~mm}$. A magnetic stirrer was used to maintain homogeneity and to assist in the ready evolution of hydrogen bubbles. At all times a power supply applied one DC to the system. The selection of $1 \mathrm{~V}$ was based on observation of the reaction (hydrogen bubbles formation and speed of reaction). After dealloying, the samples were washed with deionized water and stored in ethyl alcohol to minimize further oxidation.

\section{Results and Discussion}

3.1. Precursor Microstructure. As aforementioned, high solidification rates helped prepare the adequate microstructures of the precursor alloy. It also provided a method to study the effect of zinc solid solution on porosity formation within the primary aluminum-rich dendrites. As one can observe in a typical $\mathrm{Al}-\mathrm{Zn}$ phase diagram, zinc has a high solubility in aluminum. In a typical $\mathrm{Al}-\mathrm{Zn}$ binary alloy microstructure rich in $\mathrm{Al}$ that solidifies under normal cooling rates, primary $\mathrm{Al}$ dendrites containing dissolved zinc are surrounded by interdendritic regions containing zinc solid solution. Naturally, this nonhomogeneous microstructure would directly affect the porosity obtained by chemical dealloying since this depends on the local concentration of $\mathrm{Zn}$. In effect, if the corrosive media removes $\mathrm{Zn}$ atoms, nanoporosity evolution, as described by Erlebacher [9], would only take place inside the aluminum-rich areas while the rest of the porosity would be the result of pure $\mathrm{Zn}$ removal. Nanoporosity formation is favored when there is a complete homogeneous mixture between the two metallic elements. Such favorable microstructure was achieved by adjusting the solidification rate. Many binary systems have a natural tendency to create nonhomogeneous microstructures mostly because of phase precipitation and microsegregation, which can be prevented or minimized by rapid cooling upon solidification. In this work, fast cooling rates increase the metastable retention of $\mathrm{Zn}$ atoms in the $\mathrm{Al}$ solid solution; this reduced the amount 


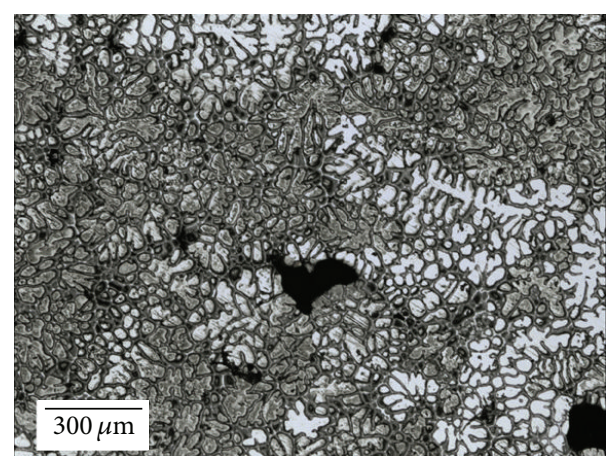

FIgURE 2: Optical microscopy image of Al-25 at.\% Zn alloy. The sample was quenched in liquid nitrogen, polished, and etched for $5 \mathrm{~s}$ with 10 wt. $\% \mathrm{NaOH}$ solution.

of zinc around the dendrites and ultimately formed a better microstructure with the potential to create nanoporosity in larger regions of the alloy sample. Figure 2 shows the resulting precursor alloy microstructure quenched in liquid nitrogen. The measured average secondary dendrite arm spacing (SDAS) was $28.81 \mu \mathrm{m}$. This SDAS value might be the result of large amounts of zinc forming solid solution with aluminum.

3.2. X-Ray Diffraction. We not only were interested in the precursor microstructure but also were curious about the effectiveness of corrosive media to selectively dissolve zinc. $\mathrm{X}$-ray diffraction (XRD) served this purpose. Since only two metals were used in the alloys, XRD provided sufficient evidence to corroborate selective removal of one of the metallic phases. This characterization technique was applied to all samples, before and after corrosion. The characteristic diffraction peaks for each metal were identified with a powder diffraction database. Figure 3 shows typical XRD spectra obtained from an $\mathrm{Al}-15 \mathrm{Zn}$ at.\% alloy before and after corrosion. The spectrum at the bottom is from a nondealloyed sample and served as a benchmark to compare other dealloyed sample diffraction patterns. XRD diffraction of samples after dealloying evinced the selective dissolution of zinc. Aluminum does not dissolve in nitric acid but rather resists the etching by passivation; this provided the necessary scenario for dealloying to occur. Complete absence of zinc peaks is observed after corrosion (upper spectrum in Figure 3). The exclusive presence of aluminum peaks appears to confirm the effective removal of zinc from the sample.

At this point it should be noted that XRD was used as one method to confirm the selective dissolution provided that $\mathrm{Al}$ and $\mathrm{Zn}$ be present only as two separate phases. Unfortunately solid solutions of $\mathrm{Zn}$ in $\mathrm{Al}$ (and vice versa) bear the same crystal structure of the matrix metal. Both spectra in Figure 3 were obtained using the same diffractometer settings, that is, power voltage, $2 \theta$ steps, and dwelling time. The widening of the bottom spectrum (alloy without selective dissolution) proves the extensive metastable supersaturation of $\mathrm{Zn}$ in the $\mathrm{Al}$ phase and vice versa (although in a lesser amount). As $\mathrm{Zn}$ is selectively removed from the alloy (upper spectrum), two occurrences reveal the successful removal: (a) the Zn-rich

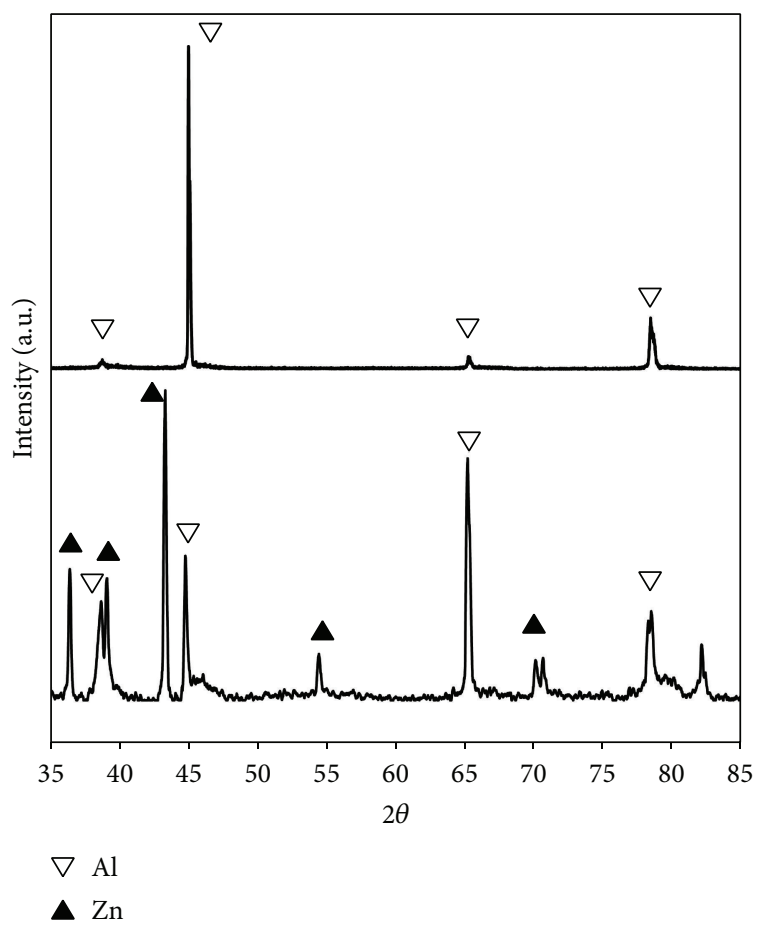

FIGURE 3: XRD patterns obtained from an $\mathrm{Al}-15 \mathrm{Zn}$ at.\% alloy before (lower spectrum) and after corrosion (upper spectrum).

phase peaks are evidently absent and (b) the $\mathrm{Al}$ peaks from the $\mathrm{Al}$ solid solution are not broad and match the expected $2 \theta$ position of pure $\mathrm{Al}$ pattern. This is a key finding since it proves that $\mathrm{Zn}$ was removed not only by dissolving the HCP interdendritic phase but also by selective dissolution of the zinc atoms dissolved in the $\alpha$-Al phase. Nonetheless, further experimental data was needed to completely understand the dissolution of zinc in aluminum and subsequently assess the selective dissolution of zinc. For this reason we used energy dispersive X-ray spectroscopy (EDS), which allowed observing species distribution throughout the samples.

3.3. EDS X-Ray Mapping. Figure 4 corresponds to an EDS analysis obtained from an Al-25 at.\% Zn alloy sample, without selective dissolution. This specimen had been quenched into liquid nitrogen to retain the metastable presence of zinc supersaturating the aluminum-rich dendrites. In this image, dendrites and interdendritic regions are readily distinguishable. Figure 4(b) shows in red the distribution of aluminum throughout the sample. While Al-rich dendrites are evident, aluminum does not appear in large amount in the interdendritic regions. Finally, Figure 4(c) shows zinc content in green evincing that this metal is present throughout the entire sample but not homogeneously; zinc segregates in the interdendritic regions and the outer dendrite boundaries.

Knowing that selective dissolution occurs when only one of the species in the binary system is dissolved, this finding suggests that selective dissolution of zinc is more aggressive on the interdendritic region. It also suggests that after selective dissolution, individual zinc atoms might remain trapped inside aluminum-rich dendrites. 

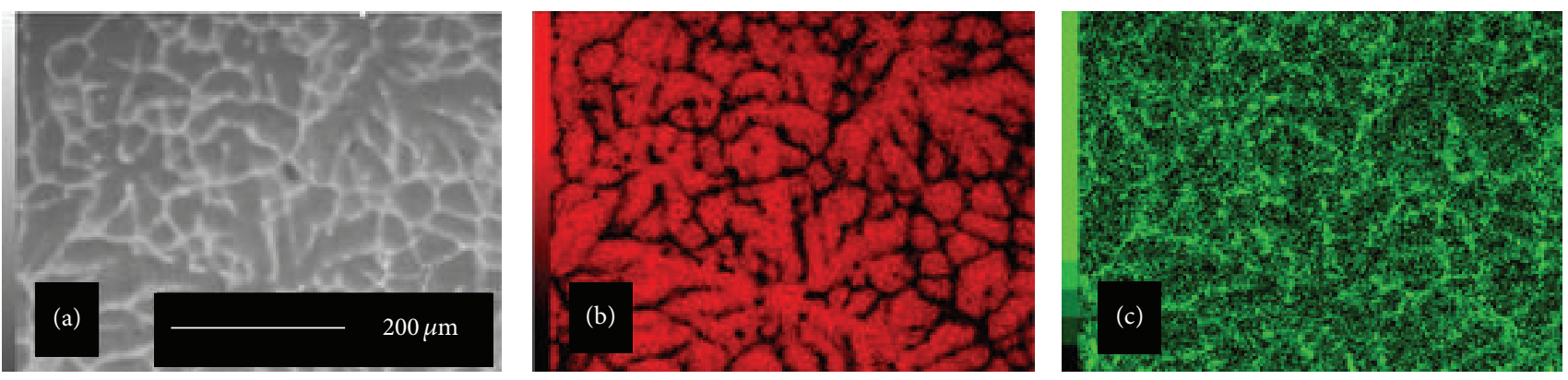

FIGURE 4: X-ray mapping of Al-25 at.\% Zn alloy quenched in liquid nitrogen. (a) Sample surface prior corrosion. (b) Distribution of aluminum. (c) Distribution of zinc.
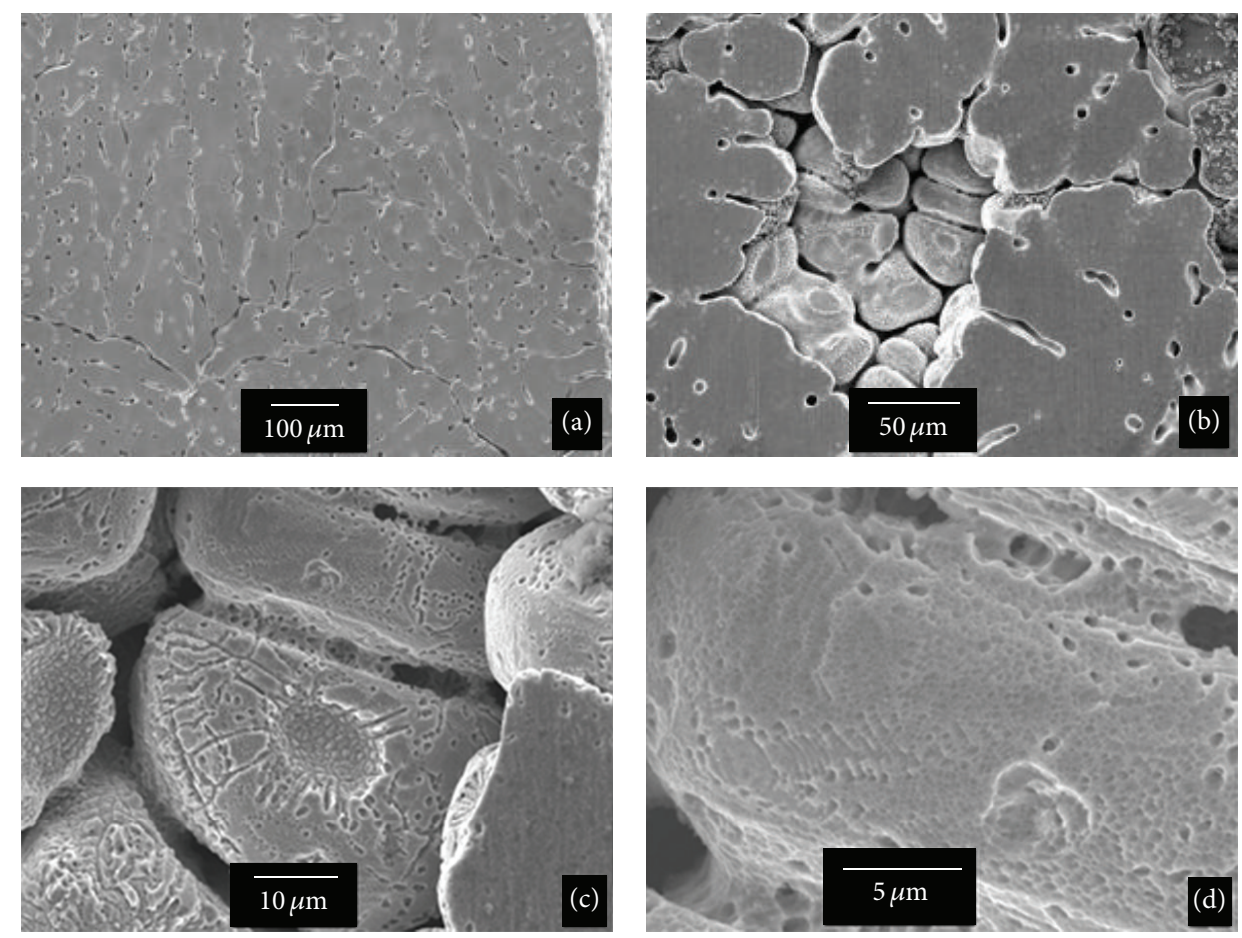

FIGURE 5: Al-15 at.\% Zn alloy quenched in liquid nitrogen solution and freely corroded in $1 \mathrm{wt} . \% \mathrm{HNO}_{3}$ solution. Zinc was selectively dissolved creating a porous structure. (a) Aluminum-rich dendrites surrounded by voids. (b) Selective removal of zinc from interdendritic regions creating a primary porosity. (c) Resultant morphology in the walls of passivated aluminum. (d) No nanoporosity was observed in this sample.

3.4. Free Corrosion Study. As aforementioned, two corrosion methods were used to observe the selective removal of zinc. Figure 5 shows the result of free corrosion. Formation of porosity via selective dissolution of zinc was readily observed in specimens with free corrosion. Figure 5(a) shows a secondary electron image of an Al-15 at.\% $\mathrm{Zn}$ alloy freely corroded in 1 wt.\% nitric acid solution. In this image, one can also observe hollow regions, which evince the removal of large zinc-rich areas. Figure 5(b) further reveals the selective dissolution of zinc by nitric acid. Deep and empty channels formed while passivated dendrites served as ligaments for an interconnected network. A characteristic morphology in the walls of passivated aluminum-rich dendrites can be also observed (Figure 5(c)). These areas, which were once the interface between aluminum-rich dendrites and zinc (i.e., before selective dissolution), seem shallowly perforated and scratched. Despite this special morphology, further inspection revealed no nanoporosity when nitric acid was used for free corrosion in any of the alloy concentrations.

3.5. Electrochemical Corrosion. The selective dissolution of zinc in electrochemical corrosion with $\mathrm{HNO}_{3}$ solution produced different results compared to free corrosion. The application of electrical potential provided the energy needed to produce smaller pores, especially on the aluminum-rich regions. Large pores are initially observed but a closer inspection reveals secondary porosity with smaller pores. This secondary porosity is concentrated inside dendrite islands and appears as the result of the applied potential. One should note that no secondary porosity was observed when no potential was applied. 

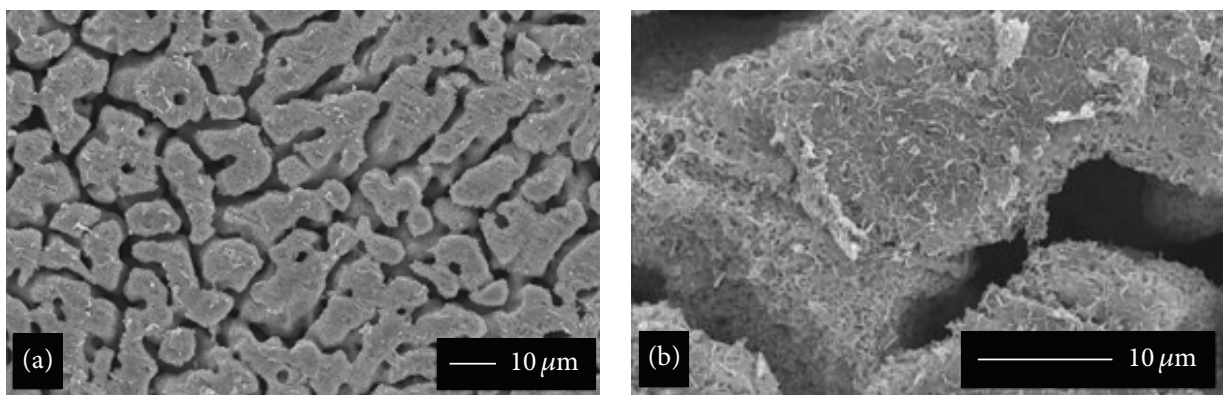

FIGURE 6: Al-35 at.\% Zn alloy quenched in liquid nitrogen and electrochemically corroded in $\mathrm{HNO}_{3}$. (a) Passivated aluminum dendrites forming interconnected three-dimensional structure. (b) Secondary porosity.
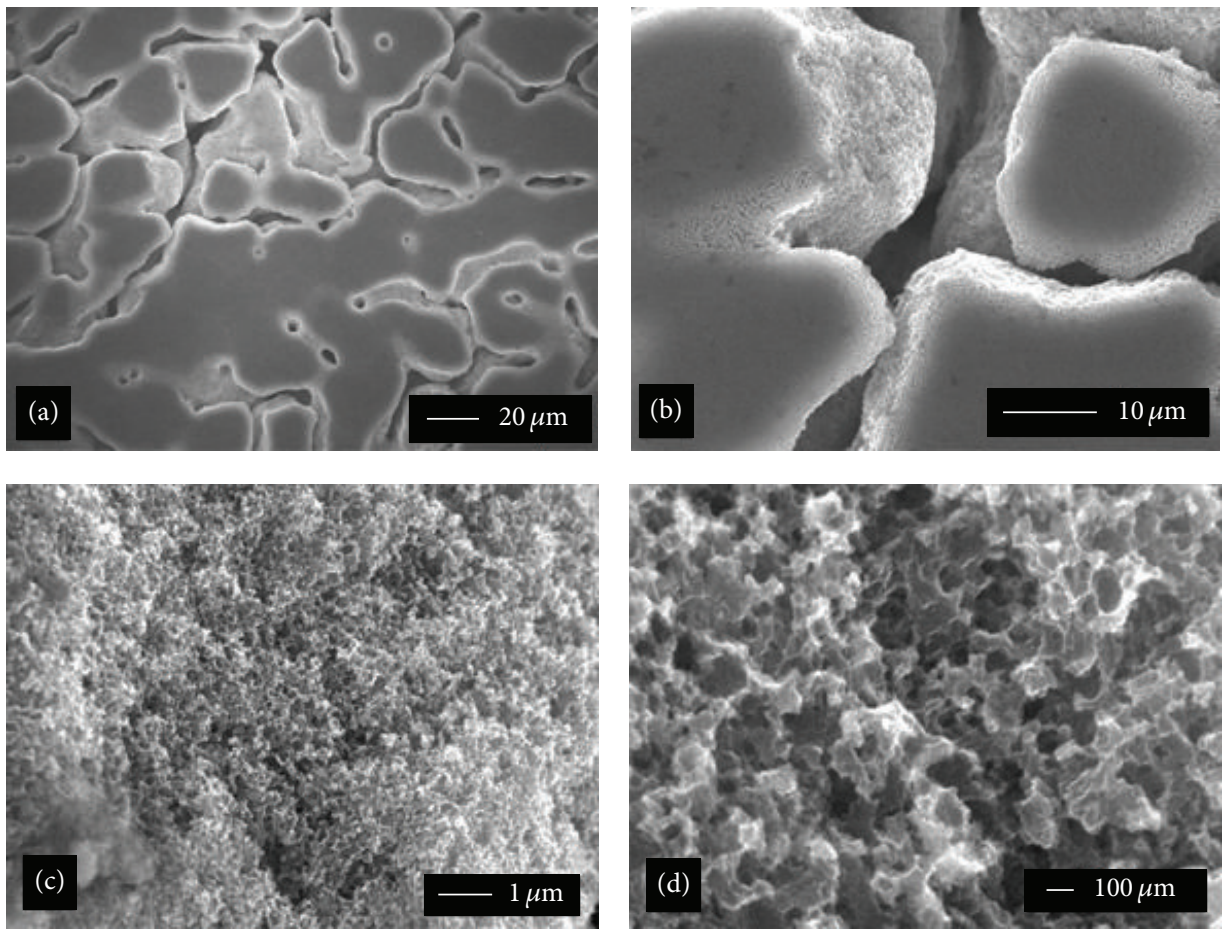

FIGURE 7: Al-25 at.\% Zn alloy quenched into liquid nitrogen and electrochemically corroded in $\mathrm{HNO}_{3}$. (a) Typical microstructure morphology after selective dissolution. (b) Roughness observed in walls suggests presence of secondary porosity. (c) Resulting morphology of dendrite walls. (d) Higher magnification of image. (c) An interconnected ligament network with nanosized pores can be observed.

Figure 6(a) shows an Al-35 at.\% Zn alloy, which was electrochemically corroded in $\mathrm{HNO}_{3}$. Dendrites are easily identifiable. Pockets of passivated aluminum-rich areas create an interconnected ligament network. These micrographs are apparently similar to those of Figure 5 with aluminum-rich dendrites separated by voids initially occupied with zinc, that is, in the parent alloy. Nonetheless, a closer examination evinced the opposite. In Figure 6(b) a smaller secondary porosity is visible with pore diameters smaller than $1 \mu \mathrm{m}$. These pores seem to be interconnected and are found everywhere in the dendrites islands especially in the outer layers.

Figure 7 shows an Al-25 at.\% Zn alloy electrochemically corroded. Secondary porosity is again evident but this time is apparently restricted to the outer regions of the dendrites. This might indicate a relationship between zinc concentration and porosity formation since one should expect microsegregation of zinc towards the last solid to form upon freezing. Canyons (deep depressions) carved by dealloying resulted in very porous walls. Figures 7 (c) and 7(d) are magnified micrographs of a wall from Figure $7(b)$. Small interconnected pores are apparent, while many pores are less than $100 \mathrm{~nm}$ in diameter. Both primary and secondary porosity were present throughout the sample and in all directions. In Figure 7(b) the presence of the secondary porosity can be observed in all the canyon walls.

\section{Conclusions}

Our results evince that porous and nanoporous aluminum can be fabricated via selective dissolution of zinc in $\mathrm{Al}-\mathrm{Zn}$ alloys using an aqueous solution of $\mathrm{HNO}_{3}$. We observed two different types of porosities: a primary, bigger porosity 
resulting from the selective removal of zinc-rich regions, and a secondary, smaller porosity formed on the outer region of the dendrites. Pores with less than $100 \mathrm{~nm}$ in diameter were observed in aluminum when electrochemically dealloyed. Coupling X-ray diffraction and EDS analysis one was able to demonstrate that even though there is zinc inside aluminumrich dendrites, almost complete removal of zinc crystals is possible via dealloying.

\section{Conflict of Interests}

The authors declare that there is no conflict of interests regarding the publication of this paper.

\section{Acknowledgment}

This material is based upon work supported by the US National Science Foundation under Grant HRD 0833112, CREST program.

\section{References}

[1] H. Qiu, C. Xu, X. Huang, Y. Ding, Y. Qu, and P. Gao, "Immobilization of laccase on nanoporous gold: comparative studies on the immobilization strategies and the particle size effects," The Journal of Physical Chemistry C, vol. 113, pp. 2521-225, 2009.

[2] R. Zeis, T. Lei, K. Sieradzki, J. Snyder, and J. Erlebacher, "Catalytic reduction of oxygen and hydrogen peroxide by nanoporous gold," Journal of Catalysis, vol. 253, no. 1, pp. 132-138, 2008.

[3] A. J. Smith, "Skeletal catalysts," in Surface and Nanomolecular Catalysis, pp. 141-158, CRC Press, Boca Raton, Fla, USA, 2006.

[4] B. Xiao and Q. Yuan, "Nanoporous metal organic framework materials for hydrogen storage," Particuology, vol. 7, no. 2, pp. 129-140, 2009.

[5] J. Weissmüller, R. C. Newman, H.-J. Jin, A. M. Hodge, and J. W. Kysar, "Nanoporous metals by alloy corrosion: formation and mechanical properties," MRS Bulletin, vol. 34, pp. 577-586, 2009.

[6] M. Hakamada and M. Mabuchi, "Preparation of nanoporous Ni and $\mathrm{Ni}-\mathrm{Cu}$ by dealloying of rolled $\mathrm{Ni}-\mathrm{Mn}$ and $\mathrm{Ni}-\mathrm{Cu}-\mathrm{Mn}$ alloys," Journal of Alloys and Compounds, vol. 485, pp. 583-587, 2009.

[7] M. Hakamada and M. Mabuchi, "Fabrication of nanoporous palladium by dealloying and its thermal coarsening," Journal of Alloys and Compounds, vol. 479, pp. 326-329, 2009.

[8] T. Aburada, J. M. Fitz-Gerald, and J. R. Scully, "Synthesis of nanoporous copper by dealloying of $\mathrm{Al}-\mathrm{Cu}-\mathrm{Mg}$ amorphous alloys in acidic solution: the effect of nickel," Corrosion Science, vol. 53, no. 5, pp. 1627-1632, 2011.

[9] J. Erlebacher, Dekker Encyclopedia of Nanoscience and Nanotechnology, CRC Press, New York, NY, USA, 2004. 

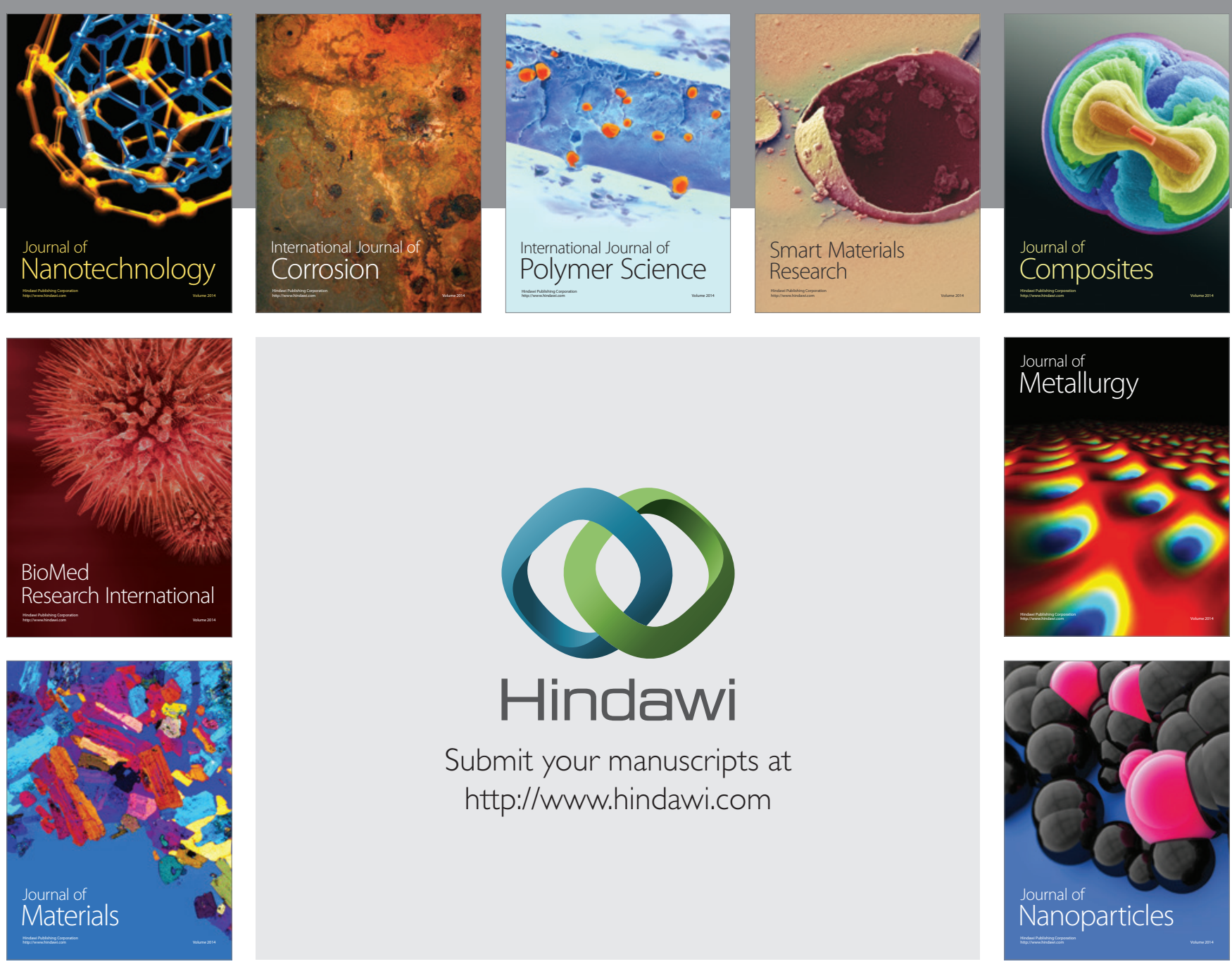

Submit your manuscripts at http://www.hindawi.com
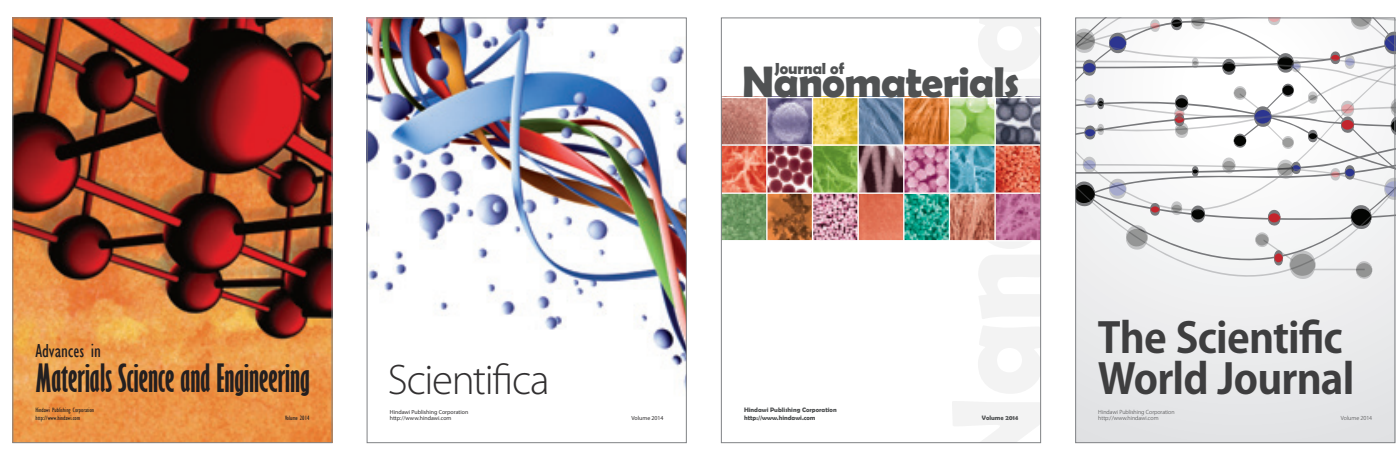

\section{The Scientific World Journal}
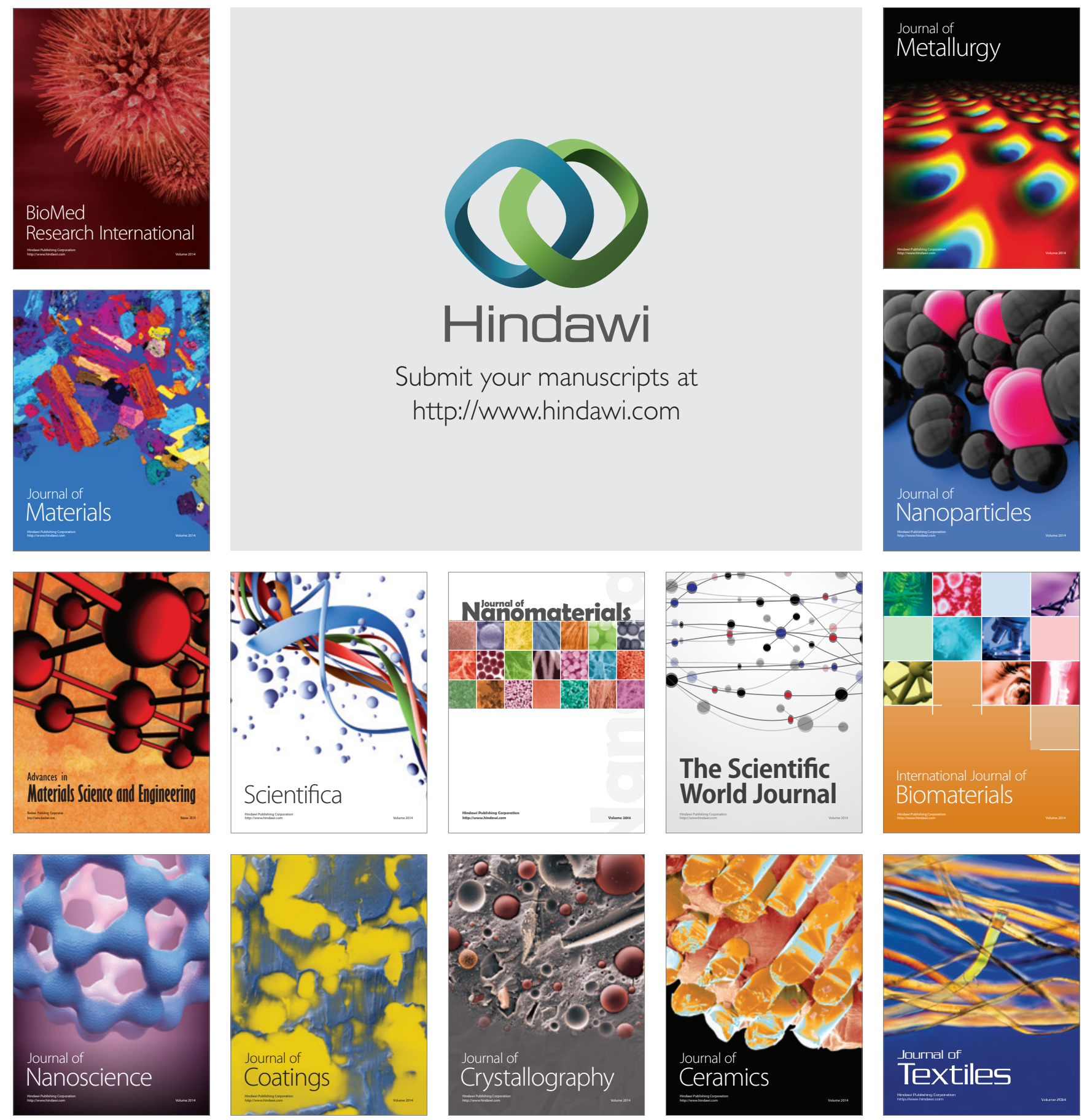